\title{
Human ventilatory response to washed and unwashed cottons from different growing areas
}

\author{
E L PETSONK, ${ }^{1}$ S A OLENCHOCK, ${ }^{1}$ R M CASTELLAN, ${ }^{1}$ D E BANKS, ${ }^{1}$ \\ JUDITH C MULL, ${ }^{1}$ J L HANKINSON, ${ }^{1}$ K C BRAGG ${ }^{2}$ H H PERKINS, ${ }^{2}$ AND \\ J B COCKE
}

From the Division of Respiratory Disease Studies, ${ }^{1}$ National Institute for Occupational Safety and Health, Morgantown, West Virginia, and Science and Education Administration, ${ }^{2}$ United States Department of Agriculture, Clemsom, South Carolina, USA

ABSTRACT Thirty volunteer subjects were exposed to controlled amounts of respirable dust gener- $\vec{p}$ ated by the carding of cotton in an experimental cardroom. Eighteen exposures each lasting six ${ }_{\circ}^{N}$ hours were performed while carding unwashed and washed cottons from the three major growing $\underset{-}{5}$ regions of the United States. Elutriated dust was analysed gravimetrically and was comparable $(0.59 \vec{z}$ $\mathrm{mg} / \mathrm{m}^{3} \pm 0.04$ ) for all exposures. Spirometry was recorded before and after each exposure. Califor- $\frac{\overrightarrow{0}}{\overrightarrow{0}}$ nia cotton resulted in a significantly smaller fall in $\mathrm{FEV}_{1}$ than cotton of the same grade from Texas $\Im$ or Mississippi. All washed cottons resulted in reduced declines when compared with unwashed $\overrightarrow{0}$ cottons. For 17 subjects breathing zone personal total dust samples were analysed for airborne $\stackrel{\circ}{\circ}$ endotoxin and compared with the individual's pulmonary function response. A significant cor- $\square$ relation between endotoxin exposure and acute decrease in FEV $_{1}$ was seen. The effect on FEV per nanogram of airborne endotoxin was greater for Mississippi cotton than for cotton from the $\bar{\partial}$ other regions. Airborne endotoxin appears to be an important determinant of acute pulmonary $\stackrel{\varrho}{\circ}$ effects of cotton dust. Water washing of cotton results in reduced airborne endotoxin and less $\stackrel{\varnothing}{\mathscr{\perp}}$ bronchoconstriction.

Certain workers employed in the processing of cotton, flax, and hemp fibres develop acute and chronic respiratory symptoms generically called byssinosis. ${ }^{1}$ In different reports the prevalence rates of byssinosis range from $2 \%$ to $90 \%{ }^{2}$ In addition to typical symptoms, acute and chronic ventilatory declines have been shown in people exposed to cotton dust. ${ }^{2}$ The variability of human responses to the inhalation of textile dusts has been related both to constitutional (individual susceptibility) and environmental factors. Increased responses to cotton dust and cotton dust extracts have been reported in cigarette smokers ${ }^{3}$ and individuals with atopy. ${ }^{4}$ Epidemiological and experimental studies have related symptom prevalence and ventilatory declines to airborne respirable dust levels. $^{5-7}$ Even after accounting for dust levels, pronounced differences exist between mills, ${ }^{5}$ and within mills at different work areas. ${ }^{8}$ Workers employed in

Accepted 27 September 1985 the earlier stages of processing, such as carding, areo more frequently and severely affected than those employed in later stages. Preprocessing of cotton, including water washing, can reduce both symptoms and decreases in ventilatory function seen over a workshift exposure. ${ }^{79}$

To define potential causes of the observed variability in responses to cotton dust, we have studieo airborne endotoxin exposures and pulmonary func tion responses of a group of volunteers exposed in model cardroom to controlled amounts of respirable dust generated by carding standard (commerciaf grade) and water washed cottons from the threo major growing regions in the United States.

\section{Methods}

Subjects were selected as previously described. ${ }^{10}$ In brief, adult volunteers were approached througho word of mouth and newspaper advertisements. $\vec{A}_{\vec{P}}$ short questionnaire was used to exclude those with के 
history of asthma or other medical contraindications to participation. Screening spirometry was performed using an Ohio 840* waterless spirometer (Ohio Medical Products Co, Lodi, NJ), with flow volume curves recorded on FM analogue tape. Recommended procedures were followed, ${ }^{11}$ and subjects with a forced expired volume in one second $\left(\mathrm{FEV}_{1}\right)$ less than $80 \%$ of predicted normal ${ }^{12}$ were excluded.

The remaining volunteers were exposed for six hours to $1 \mathrm{mg} / \mathrm{m}^{3}$ of respirable (elutriated) dust from standard Mississippi cotton. On a separate occasion they were exposed for six hours in a dust free room. Spirometry was performed before and after each exposure. Thirty subjects were selected on the basis of their ventilatory responses to these screening exposures. Subjects showing at least a $5 \%$ fall in $\mathrm{FEV}_{1}$ after an exposure of six hours to $1 \mathrm{mg} / \mathrm{m}^{3}$ of standard cotton dust, relative to their change in $\mathrm{FEV}_{1}$ after no cotton exposure, were selected for participation.

The study took place over a six week period in January and February 1981. All exposures were performed in the model cardroom at the US Department of Agriculture Cotton Quality Research Station, Clemson, SC. Duplicate exposures were made to all cottons, and the subjects were unaware of the specific type of cotton being carded. During the study, spirometry was performed before and after six hour cotton dust exposures on Mondays, Wednesdays, and Fridays. After each exposure, the cardroom was thoroughly cleaned, and on Tuesday or Thursday, or both, spirometry was performed before and after the subjects had remained for six hours in the cardroom with no cotton being carded (control exposure). The subjects sat in chairs placed around the periphery of the cardroom and to ensure equal exposures each subject moved two or three seats about every 30 minutes, so that they made a complete circuit during the exposure. Subjects could leave the cardroom only for short restroom breaks, and smoking was forbidden during the exposure period.

Dust sampling was performed continuously with four vertical elutriators (flow rate, $7 \cdot 4$ litres a minute) located around the cardroom. A constant carding rate was used. Dust concentration, determined approximately hourly as the mean value from the four elutriators, was maintained at the desired level by varying the exhaust ventilation. Seventeen of the 30 subjects also wore personal samplers (MSA type $\mathrm{G}$, with an open faced cassette; Mine Safety Appliance $\mathrm{Co}$, Pittsburgh, $\mathrm{Pa}$ ) for breathing zone total airborne dust collections. ${ }^{13}$

\footnotetext{
* Mention of company names or products does not constitute endorsement by the National Institute for Occupational Safety and Health.
}

Strict low middling grade cotton was obtained from the three major growing areas of the United States: Mississippi River Delta, Texas High Plains, and California San Joaquin Valley. Cotton was harvested in Texas by mechanical stripping, whereas in California and Mississippi mechanised pickers were used. All bales from a region were blended in the usual manner. Samples of cotton from each region were then further treated by washing with water at $60^{\circ} \mathrm{C}\left(140^{\circ} \mathrm{F}\right)$ on a rayon washing system, using 50 pounds of water for each pound of cotton. After washing, a standard textile finish was applied (SSC Finish 641; SSC Industries, Inc, East Point, Ga).

Two samples of the Mississippi cotton were subjected to washing at a higher water to fibre ratio, 65 pounds of water per pound of cotton, one at $60^{\circ} \mathrm{C}$ and one at $28^{\circ} \mathrm{C}\left(80^{\circ} \mathrm{F}\right)$. Finally, a sample of Mississippi cotton was washed using a wool scouring system. The water to fibre ratio used in this system was not estimated.

The six hour personal samples were analysed gravimetrically and total endotoxin content of each filter was assessed. For the latter analysis, filters from the personal air samplers were extracted with $10 \mathrm{ml}$ ster-

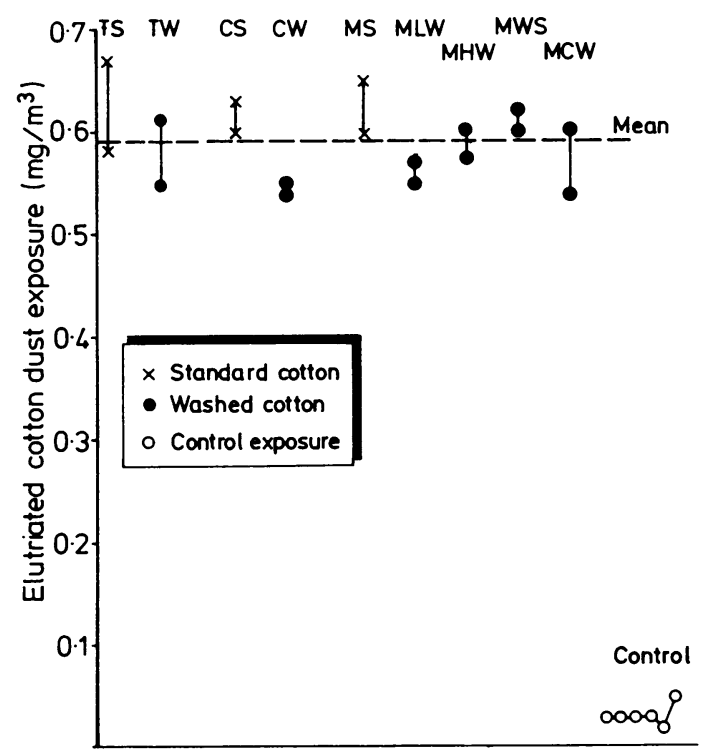

Fig 1 Variability in elutriated dust exposures in a model card room. TS Texas standard (unwashed) cotton; TW Texas washed cotton; CS California standard (unwashed) cotton; W California washed cotton; MS Mississippi standard (unwashed) cotton; $M L W$ Mississippi washed cotton, low water ratio; MHW Mississippi washed cotton, high water ratio; MWS Mississippi washed cotton, wool scouring system; MCW Mississippi washed cotton, cooler water temperature; and MW Mississippi washed cotton, all conditions. 


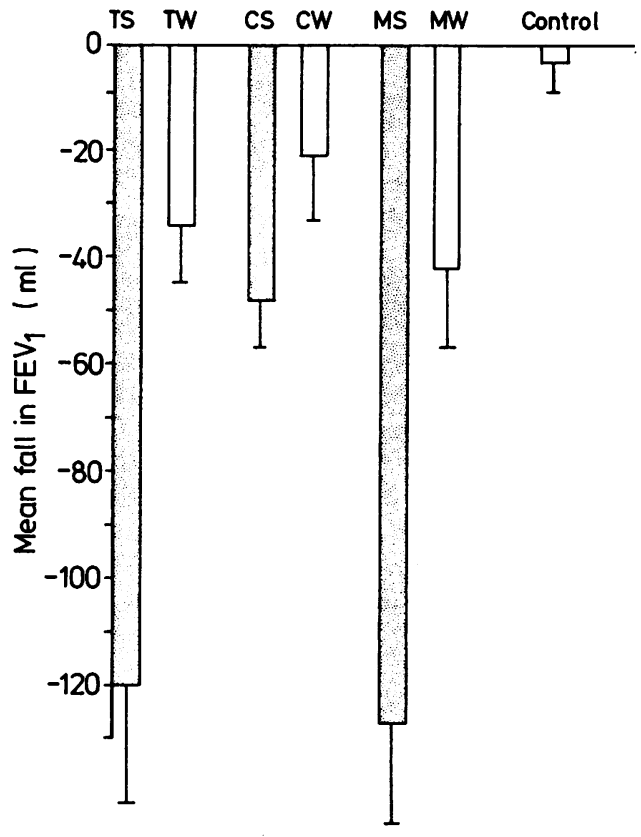

Fig 2 Ventilatory response to standard and washed cotton dust (mean $\pm S E M$ for 30 subjects). (For abbreviations, see fig 1.)

ile, non-pyrogenic water (Travenol Laboratories, Inc, Deerfield, IL) by rocking at room temperature for 60 minutes. Sterile, pyrogen free plastic ware was used throughout the assay. The fluid was centrifuged at $1000 \mathrm{~g}$ for 10 minutes and the Gram negative bacterial endotoxin content of the supernatant fluid was quantified in duplicate by a spectrophotometric modification of the Limulus amoebocyte lysate gel test (Pyrostat; Millipore Corp, Bedford, Mass). Sample results were analysed by linear regression, compared with a standard curve, and reported as nanograms of US reference endotoxin.

Data were analysed by the statistical analysis system (SAS Institute, Inc, Cary, NC) using linear regression and analysis of variance.

\section{Results}

The overall mean dust concentration for the dust exposures was $0.59 \mathrm{mg} / \mathrm{m}^{3}$, and measurements for individual exposures were similar (fig 1). The washed cottons resulted in less dust generation and required a corresponding reduction in cardroom exhaust ventilation to maintain the desired dust concentration.

Significant decrements in ventilatory function, as

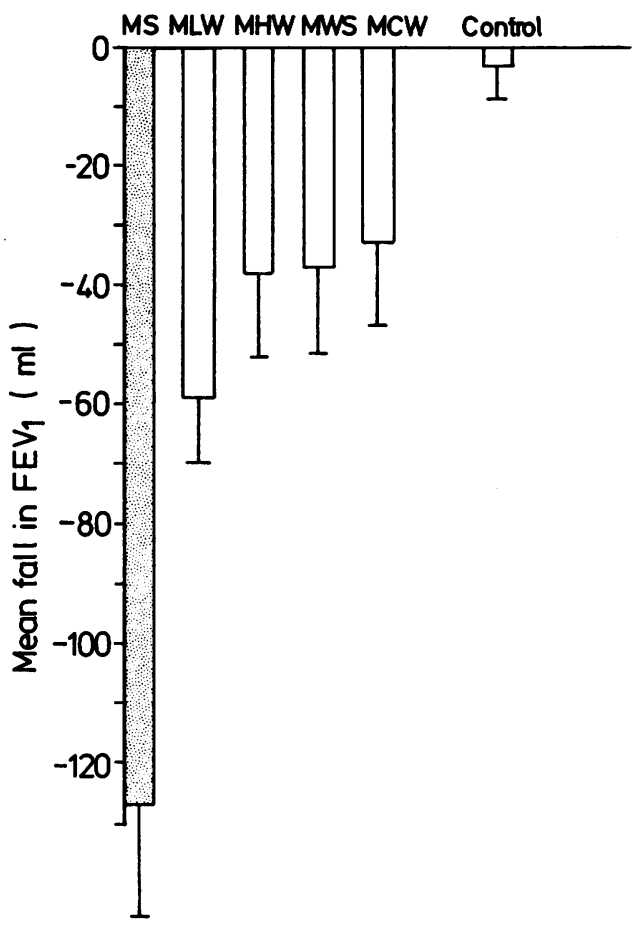

Fig 3 Effect of various washing conditions on ventilatory response to Mississippi cotton dust (mean \pm SEM for 30 subjects). (For abbreviations see fig 1.)

measured by $\mathrm{FEV}_{1}$, were seen during exposures to the standard (unwashed) cottons (fig 2). The ventilatory response to California cotton, however, was significantly less than that to either Texas or Missis- $\frac{\mathbb{D}}{3}$ sippi cotton $(p<0.05)$. Water washing reduced the ventilatory decline over the six hour exposure period 3 . for each regional cotton $(p<0.01)$. Since all subjects were not present during each exposure day, an anal- $\bar{z}$ ysis was made using only the responses of 16 subjectso who were present during all exposures. The overall results were unchanged.

The effect of the various washing conditions on the responses to the Mississippi cotton was assessed. $N$ Washing by each method resulted in a highly N significant reduction in the ventilatory decline com-N pared with the standard (unwashed) Mississippi cot- $\omega$ ton (fig 3). There was no statistically significant $<$ difference among the four washing conditions with regard to decrement in FEV 1 over exposure. Com- $\$$ pared with the other washed Mississippi cottons, the low water ratio $(50: 1)$ washed cotton resulted in the greatest fall in $\mathrm{FEV}_{1}$, but this difference was not sta- $\overrightarrow{\mathrm{D}}$ tistically significant $(p>0 \cdot 16)$. There was no $\frac{\rho}{\mathrm{O}}$ 


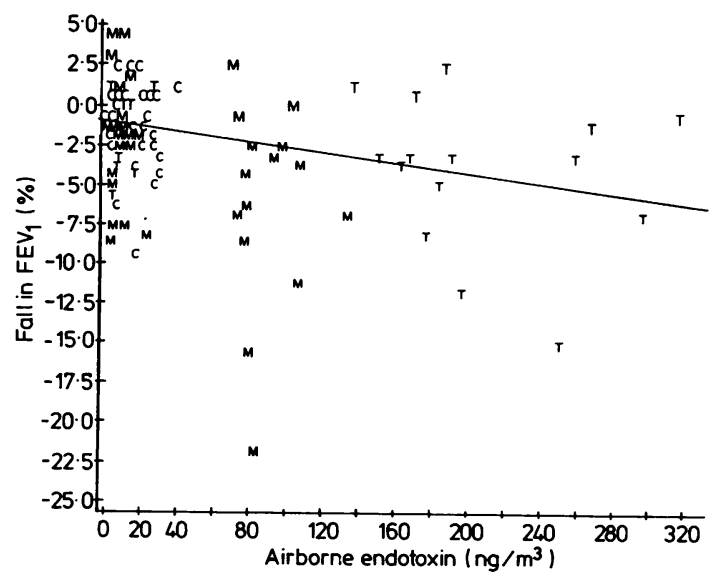

Fig 4 Decrements in FEV as a function of airborne endotoxin exposures for washed and unwashed cotton from California (C), Mississippi (M), and Texas (T) (17 subjects).

significant variation in the baseline morning value of FEV $_{1}$ over the series of exposures $(p>0.51)$.

Breathing zone airborne endotoxin levels were determined for the 17 individuals from whom personal sampler filters were available. Water washing of the cottons from each region resulted in a significant reduction of airborne endotoxin. Personal filter samples obtained during exposures to cotton from California, Texas, and Mississippi showed mean reductions in endotoxin content of $65 \%, 95 \%$, and $96 \%$ respectively, when washed cotton was compared with unwashed cotton from the same geographical region. For the Mississippi cotton, the various washing conditions resulted in an 83-96\% decrease in endotoxin per milligram of airborne cotton dust. ${ }^{13}$

When analysed as airborne endotoxin levels $\left(\mathrm{ng} / \mathrm{m}^{3}\right)$ for all washed and unwashed cottons, there was a highly significant relation $(p<0.01)$ between individual endotoxin exposures and percentage declines in $\mathrm{FEV}_{1}$ over the six hour exposure. Although there was considerable scatter in the data (fig 4), mean values generally showed a similar
Table 2 Effect of wash conditions on airborne endotoxin levels and change in FEV,

\begin{tabular}{lll}
\hline Wash conditions & Endotoxin $\left(\mathrm{ng} / \mathrm{m}^{3}\right)$ & $\begin{array}{l}\text { FEV } \\
(\%)\end{array}$ \\
\hline Unwashed & & change \\
$28 ; 65: 1$ & $87.6 \pm 4.5 \ddagger$ & $-6.1 \pm 1.5 \ddagger$ \\
$60 ; 65: 1$ & $12.5 \pm 0.8$ & $-0.9 \pm 1.3$ \\
$60 ; 50: 1$ & $10.6 \pm 1.1$ & $-1.6 \pm 0.9$ \\
$60 ;$ Wool scouring & $3.8 \pm 0.5$ & $-1.3 \pm 0.9$ \\
\hline
\end{tabular}

*Mississippi cotton: temperature $\left({ }^{\circ} \mathrm{C}\right)$; water to fibre ratio by weight. $+\left(\left(\right.\right.$ Postexposure FEV $_{1}$ - pre-exposure $\left.\mathrm{FEV}_{1}\right) /$ pre-exposure $\left.^{\mathrm{F} E V_{1}}\right) \times$

$\ddagger$ Mean \pm SEM; $\mathrm{n}=16$.

relation (tables 1 and 2). After accounting for the effect of airborne endotoxin, there was no significant difference between the cottons from the three regions in mean decline in $\mathrm{FEV}_{1}$ during exposure $(\mathrm{p}>0 \cdot 10)$. Linear regression of endotoxin versus decline in $\mathrm{FEV}_{1}$ was performed separately for exposures to cotton from each region. The slope of the linear regression for the Mississippi cotton was greater than that for the Texas cotton $(p<0.05)$, indicating a larger decline in $\mathrm{FEV}_{1}$ per nanogram of airborne endotoxin.

\section{Discussion}

We have shown significant differences in the ability of cottons of similar grade from different growing regions in the United States to produce declines in ventilatory capacity over a workshift exposure. Water washing resulted in reduced effects of cotton from each region. The observed differences are likely to be related to the characteristics of the cottons, since dust concentration, subjects, and carding rate were similar in all exposures. Although somewhat different harvesting methods were used for Texas cotton, there was no significant difference in ventilatory decline from Mississippi cotton. California cotton, however, resulted in a significantly smaller response than either of the other cottons.

Recent investigations have focused on the possible

Table 1 Airborne endotoxin and change in $F E V_{1}$ by type of cotton exposure

\begin{tabular}{|c|c|c|c|}
\hline Cotton type & $\begin{array}{l}\text { No of subjects } \\
\text { exposed }\end{array}$ & Endotoxin (ng/m $\left.\mathrm{m}^{3}\right)$ & $\begin{array}{l}\text { FEV } \\
(\%)^{1}\end{array}$ \\
\hline $\begin{array}{l}\text { California standard (unwashed) cotton } \\
\text { California washed cotton } \\
\text { Mississippi standard (unwashed) cotton } \\
\text { Mississippi washed cotton, high water ratio } \\
\text { Texas standard (unwashed) cotton } \\
\text { Texas washed cotton } \\
\text { Control }\end{array}$ & $\begin{array}{l}17 \\
16 \\
16 \\
16 \\
17 \\
16 \\
17\end{array}$ & $\begin{array}{r}23.7 \pm 1.9 \dagger \\
7.3 \pm 1.0 \\
87.6 \pm 4.5 \\
10.6 \pm 1.1 \\
202.2 \pm 13.2 \\
10.8 \pm 2.1\end{array}$ & $\begin{array}{l}-2.5 \pm 0.6+ \\
-0.1 \pm 0.6 \\
-6.1 \pm 1.5 \\
-1.6 \pm 0.9 \\
-4.2 \pm 1.2 \\
-1.3 \pm 0.6 \\
-0.8 \pm 0.6\end{array}$ \\
\hline
\end{tabular}

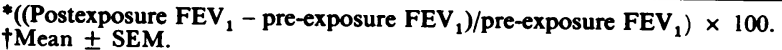


role of microbiological contamination in the aetiology of respiratory disease in textile workers. ${ }^{14}$ Cinkotai et al and Haglind et al correlated airborne viable Gram negative bacteria with symptoms of byssinosis in cotton mills. ${ }^{1516}$ They found a poor correlation between airborne endotoxin and symptoms, but did not measure ventilatory changes. Another study found that including baled cotton Gram negative bacterial counts with gravimetric elutriated dust in an exposure index produced an improved correlation with $\mathrm{FEV}_{1}$ shift change in cotton textile mill workers. ${ }^{17}$

In our study the unwashed California cotton resulted both in lower airborne endotoxin and smaller ventilatory declines than the other standard cottons, despite equivalent gravimetric dust exposures as measured by vertical elutriator. After washing, decreases in endotoxin content of cotton dust from each region correlated with lesser declines in $\mathrm{FEV}_{1}$. No significant mean effect remained after endotoxin content differences of the regional cottons were taken into account. A difference was suggested, however, when linear regression analysis was performed separately for cotton from each region.

Endotoxin as measured by Limulus amoebocyte lysate assay appears, in the present study, to account for much of the variation in acute effects of cottons from different regions. The biological activity of cotton dust in causing ventilatory declines is correlated with airborne endotoxin levels. When these levels were decreased either naturally (as with the California standard cotton) or by washing, biological activity tended to follow this decrease.

Inhalational exposure to endotoxin causes an increase in the number of leukocytes on respiratory membranes in animals and man. ${ }^{14}$ Leukocyte recruitment on the nasal mucosa has been shown in people occupationally exposed to cotton dust. ${ }^{18}$ Helander $e t$ al investigated the pulmonary effects of endotoxins derived from bacteria known to contaminate cotton in animals. ${ }^{19}$ They found pronounced differences in the recruitment of leukocytes to the respiratory tract by various endotoxins derived from these bacteria, and related these differences to the specific fatty acid content of the endotoxins. Millner et al have reported qualitative and quantitative differences in bacterial contaminants of cottons from different growing regions. ${ }^{20}$ It has been suggested that the different potency of regional cottons in producing ventilatory declines may relate to differences between the endotoxins with which they are contaminated. ${ }^{21}$

An additional explanation for our observed differences in the biological activity of cottons from various growing regions relates to our use of total personal dust samples for the endotoxin assay. These samples represent total airborne dust, and not just the $\frac{3}{\infty}$ smaller fraction capable of depositing in the lung. The ?

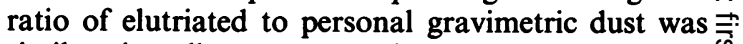
similar in all exposures, however, making this explanation less plausible.

At present, airborne endotoxin appears to be an $\frac{\bar{\sigma}}{\bar{\omega}}$ important independent measure of cotton dust bio- $\frac{\sigma}{\sigma}$ logical potency, as indicated by acute ventilatory $\stackrel{\mathbb{Q}}{\circ}$ declines, when compared with standard gravimetric $\%$ measures alone. The finding of a reduction in acute $\vec{\circ}$ responses after exposure to dust from washed cotton may help to clarify the relative roles of the various $\vec{\omega}$ cotton contaminants. The restoration of the bron- $\frac{\rho}{\circ}$ choconstrictor effects from exposure to washed cot- $\frac{\mathbb{D}}{7}$ ton which had been experimentally recontaminated with purified bacterial endotoxin would support the role of this substance in producing acute declines in $\omega$ ventilatory function in cotton workers. The relation, if any, between airborne endotoxin and other effects $ᄋ$ of cotton dust, such as irreversible ventilatory impairment, remains to be clarified. ${ }^{22}$

Requests for reprints to: Dr EL Petsonk, $944 \stackrel{\frac{\pi}{丂}}{د}$ Chestnut Ridge Road, Morgantown, WV 26505, USA.

\section{References}

${ }^{1}$ Roach SA, Schilling RSF. A clinical and environmental study of byssinosis in the Lancashire cotton industry. $\mathrm{Br} J$ Ind $\mathrm{Med} \stackrel{\mathrm{D}}{\mathrm{Q}}$ 1960;17:1-9.

${ }^{2}$ Bouhuys A, Zuskin E. Byssinosis: occupational lung disease in tex- $\overrightarrow{\bar{O}}$ tile workers. In: Frazier CA, ed. Occupational asthma. New York: Van Nostrand Reinhold, 1980:33-52.

${ }^{3}$ Merchant JA, Lumsden JC, Kilburn KH, et al. An industrial study of the biological effects of cotton dust and cigarette smoke. exposure. J Occup Med 1973;15:212-21.

${ }^{4}$ Jones RN, Butcher BT, Hammond YY, et al. Interaction of atopy $\frac{\mathbb{D}}{3}$ and exposure to cotton dust in the bronchoconstrictor response. Br J Ind Med 1980;37:141-6.

5 Jones RN, Diem JE, Glindmeyer H, et al. Mill effect and dose-그. response relationship in byssinosis. $\mathrm{Br} J$ Ind $\mathrm{Med}_{\text {กे }}$ 1979;36:305-13.

${ }^{6}$ Merchant JA, Lumsden JC, Kilburn KH, et al. Dose-response studies in cotton textile workers. J Occup Med 1973;15:222-30. 음

${ }^{7}$ Merchant JA, Lumsden JC, Kilburn KH, et al. Preprocessing cot- $D$ ton to prevent byssinosis. Br J Ind Med 1973;30:237-47.

${ }^{8}$ Imbus HR, Suh MW. Byssinosis: a study of 10137 textile workers. Arch Environ Health 1973;26:183-91.

${ }^{9}$ Boehlecke B, Cocke J, Bragg K, et al. Pulmonary function response to standard and washed cotton dust. (Abstract). Am Rev Respir Dis 1981;123part 2:152.

${ }^{10}$ Boehlecke B, Cocke J, Bragg K, et al. Pulmonary function $\frac{\omega}{\sigma}$ response to dust from standard and closed boll harvested cotton Chest 1981;79:77S-81S.

${ }^{11}$ American Thoracic Society. 'Snowbird workshop on standard- $\frac{\mathrm{C}}{\mathrm{D}}$ ization of spirometry.' Am Rev Respir Dis 1979;119:831-8.

12 Knudsen RJ, Slatin RC, Lebowitz MD, Burrows B. The maximal expiratory flow volume curve. Am Rev Respir Dis 1976;113:587-600.

13 Olenchock SA, Mull JC, Jones WG. Endotoxin in cotton: washing effects and size distribution. Am J Ind Med 1983;4:515-21. 
${ }^{14}$ Rylander R. Bacterial toxins and etiology of byssinosis. Chest 1981;79:34S-38S.

${ }^{15}$ Cinkotai FF, Lockwood MG, Rylander R. Airborne microorganisms and prevalence of byssinotic symptoms in cotton mills. Am Ind Hyg Assoc J 1977;38:554-9.

${ }^{16}$ Haglind P, Lundholm M, Rylander R. Prevalence of byssinosis in Swedish cotton mills. Br J Ind Med 1981;38:138-43.

${ }^{17}$ Rylander R, Imbus HR, Suh MW. Bacterial contamination of cotton as an indicator of respiratory effects among card room workers. Br J Ind Med 1979;36:299-304.

${ }^{18}$ Merchant JA, Halprin GM, Hudson AR, et al. Responses to cotton dust. Arch Environ Health 1975;30:222-9.
${ }^{19}$ Helander I, Salkinoja-Salonen M, Rylander R. Chemical structure and inhalation toxicity of lipopolysaccharides from bacteria on cotton. Infect Immun 1980;29:859-62.

${ }^{20}$ Milliner PD, Ericson KE, Marsh PB. Bacteria on closed-boll and commercially harvested cotton. Appl Environ Microbiol 1982;44:355-62.

${ }^{21}$ Castellan RM, Olenchock SA, Hankinson JL, et al. Acute bronchoconstriction induced by cotton dust: dose-related responses to endotoxin and other dust factors. Ann Intern Med 1984;101:157-63.

${ }^{22}$ Kilburn KH. Byssinosis: causes and practical control. Ann Intern Med 1984;101:252-4. 